\title{
The Association between Glucose Levels and Adverse Pregnancy Outcomes in Nondiabetic Twin Pregnancies
}

\author{
Kevin Cheung, BA ${ }^{1}$ Nathan S. Fox, MD ${ }^{1,2}$ \\ ${ }^{1}$ Department of Obstetrics, Gynecology, and Reproductive Science, \\ Icahn School of Medicine at Mount Sinai, New York City, New York \\ Address for correspondence Kevin Cheung, BA, Maternal Fetal \\ Medicine Associates, PLLC, 70 East 90th Street, New York, NY 10128 \\ 2 Maternal Fetal Medicine Associates, PLLC, New York City, New York \\ (e-mail: kevin.cheung@icahn.mssm.edu).
}

Am J Perinatol Rep 2020;10:e217-e223.

\begin{abstract}
Keywords

- gestational diabetes

- gestational diabetes mellitus screening

- hyperglycemia

- multiple gestation

- twin pregnancy

Objective The aim of this study is to determine if hyperglycemia in twin pregnancies without gestational diabetes mellitus (GDM) is associated with an increased risk of adverse pregnancy outcomes.

Study Design Retrospective cohort study of twin pregnancies in a single MaternalFetal Medicine practice between 2005 and 2019 who underwent two-step GDM screening at 24 to 28 weeks. We excluded women with pregestational or gestational diabetes. We examined the association between maternal glycemia and adverse pregnancy outcomes. Glycemia was defined as the 1-hour GCT in all women, and each of the four values of the 3-hour OGTT in women who failed the GCT ( $\geq 130 \mathrm{mg} / \mathrm{dL}$ ). Primary outcomes were preeclampsia, cesarean delivery, and neonatal hypoglycemia in either twin. Statistical tests used included Pearson's correlation, Student's t-test, Mann-Whitney $\mathrm{U}$ test, Chi-square test for trend, and logistic regression.

Results A total of 847 women underwent a GCT and 246 women underwent an OGTT. Increasing maternal glucose levels had no positive association with adverse outcomes. Women with preeclampsia, cesarean delivery, and neonatal hypoglycemia did not have higher mean GCT or OGTT values than women without these outcomes. There was no increased risk of adverse outcomes with increasing quartiles of the GCT or OGTT values. Conclusion In women with twin pregnancies without GDM, elevated maternal glucose levels are not associated with preeclampsia, cesarean delivery, or neonatal hypoglycemia. The altered physiology of twin gestations may modify the effect of maternal hyperglycemia on perinatal outcomes as compared with singleton pregnancies. Current approaches to screening for and treating GDM during pregnancy might not adequately account for these unique considerations among twins.
\end{abstract}

Gestational diabetes mellitus (GDM) is a common complication seen in pregnancy, with an estimated incidence of 6 to $7 \%{ }^{1}$ GDM in singleton pregnancies has been associated with adverse pregnancy outcomes, including macrosomia, birth injury, cesarean delivery, neonatal hypoglycemia, and preeclampsia. ${ }^{2-5}$ Increasing rates of obesity and advanced maternal age during pregnancy in U.S. women contribute to a rising incidence of maternal hyperglycemia and GDM. ${ }^{6}$

received

March 10, 2020 accepted after revision May 24, 2020
DOI https://doi.org/

10.1055/s-0040-1714712. ISSN 2157-6998.
In 2008, the Hyperglycemia and Adverse Pregnancy Outcomes (HAPO) study, a large multicenter study, found that maternal hyperglycemia during pregnancy even less severe than in GDM is also associated with adverse pregnancy outcomes. The authors reported continuous positive associations between maternal glucose levels, measured by a 75-g and 2-hour oral glucose tolerance test (OGTT), and several adverse outcomes, including birthweight greater than 90th
Copyright $\odot 2020$ by Thieme Medical Publishers, Inc., 333 Seventh Avenue, New York, NY 10001, USA. Tel: +1(212) 760-0888.
License terms

()(1) $\Theta \circledast$ 
percentile, cesarean delivery, neonatal hypoglycemia, neonatal hyperinsulinemia, birth injury, and preeclampsia. ${ }^{5}$

As the incidence of twin pregnancies increases, ${ }^{7}$ the incidence of twin pregnancies complicated by hyperglycemia and GDM is also likely to increase. Twin deliveries account for 3.4\% of all live births in the United States. ${ }^{8}$ While the data are conflicting, there is evidence that twin pregnancies may be at an increased risk of GDM, likely due to increased placental mass and diabetogenic hormones such as human placental lactogen. ${ }^{9-11}$ Hiersch et al recently found that the increased risk of GDM among twin pregnancies was mainly due to a higher incidence of mild, diet-treated GDM, and suggested that the mildly increased glucose intolerance may be a beneficial physiologic response to increased maternal metabolic rates and increased glucose demand for two fetuses. ${ }^{12}$

Data on outcomes in twin pregnancies complicated by maternal hyperglycemia or GDM are less certain than the data for singletons. While GDM in singletons increases the risk of adverse outcomes such as macrosomia and birth injury, these outcomes may not be as clinically relevant in twin gestations, which are in contrast at a higher risk for small for gestational age (SGA) neonates and prematurity. ${ }^{13-15}$ The amplification of certain physiological changes in twin pregnancies may modulate the impact of hyperglycemia and GDM in twins, thus limiting the generalizability of findings gathered from singleton pregnancies. ${ }^{16,17}$ In fact, large studies on the screening, treatment, and management of maternal hyperglycemia and GDM often do not include twins, ${ }^{18}$ or include few twins and do not analyze them separately. ${ }^{3}$ The HAPO study, for instance, did not include any twin pregnancies. ${ }^{5}$

While the HAPO study demonstrated a positive association between maternal glycemia and adverse pregnancy outcomes in singletons, it remains unclear whether these findings apply to twin gestations. The objective of this study was to determine if the maternal glucose level in twin pregnancies without GDM is associated with an increased risk of adverse pregnancy outcomes.

\section{Materials and Methods}

After Biomedical Research Alliance of New York Institutional Review Board approval was obtained, we reviewed the charts of all patients with twin pregnancies delivered by one maternal fetal medicine practice from June 2005 (when our electronic medical record was established) through March 2019. Baseline characteristics and pregnancy outcomes were obtained from our computerized medical record. We excluded all patients with pregestational diabetes or gestational diabetes, monoamniotic twins, delivery $<24$ weeks of gestation, and twin-to-twin transfusion.

Over the course of the study period, we followed a two-step GDM screening protocol per standard recommendations. ${ }^{1}$ All patients underwent a nonfasting 1-hour and 50-g glucose challenge test (GCT) between 24 and 28 weeks of gestation or earlier if indicated. All patients with a GCT $\geq 130 \mathrm{mg} / \mathrm{dL}$ underwent a diagnostic fasting 3-hour and 100-g OGTT. A diagnosis of GDM was given if two out of four values were abnormal based on Carpenter and Coustan cutoffs: fasting $\geq 95,1$-hour $\geq 180,2$-hour $\geq 155$, and 3 -hour $\geq 140 \mathrm{mg} / \mathrm{dL} .{ }^{19} \mathrm{In}$ our practice, all patients diagnosed with GDM receive nutritional counseling, begin fingerstick monitoring, and are given medication intervention if adequate control is not achieved through dietary intervention alone. This study included patients with a normal GCT, as well as patients who failed the GCT but had a normal 3-hour OGTT. We excluded patients diagnosed with GDM through the two-step screening.

We examined the association between maternal glycemia and adverse pregnancy outcomes. Glycemia was defined as the 1-hour GCT value in all women, and each of the additional four values of the 3-hour OGTT in women who failed the GCT and underwent OGTT testing. We did not include any GCT or OGTT values from testing done prior to 24 weeks (as it is done in certain higher risk patients). However, we did include the testing done after 24 weeks for these women. For example, if a woman had an early GCT at 14 weeks and failed it and then passed her OGTT at 15 weeks, we did not include any of these results in the analysis, but we did include her OGTT results from 24 to 28 weeks, assuming she did not get diagnosed with GDM.

The primary outcomes for this study were preeclampsia, cesarean delivery, and neonatal hypoglycemia in either twin. Preeclampsia was defined as new-onset hypertension along with proteinuria or severe features (headache, abnormal laboratory values, and severe hypertension). Neonatal hypoglycemia was defined as being present if there was a notation of neonatal hypoglycemia in the medical record, as well as either a glucose value less than $40 \mathrm{mg} / \mathrm{dL}$ or treatment for hypoglycemia.

In our practice, prenatal care and delivery management for twins without GDM are not altered based on the actual GCT or OGTT values. We do not repeat GCT or OGTT screening after 28 weeks if the original screen at 24 to 28 weeks was normal. All patients with twin pregnancies have formal nutrition counseling, but this is typically done prior to screening for GDM. Checking blood glucose is not part of routine follow up for twin pregnancies without GDM.

We first used Pearson's correlation to test the relationship between each measure of maternal blood glucose level (GCT, fasting OGTT, 1-hour OGTT, 2-hour OGTT, and 3-hour OGTT), and each of the following outcomes: gestational age at delivery, birthweight of larger twin, and birthweight of smaller twin. Then, using the Student's $t$-test, we compared mean values for all five glucose measures between patients who did and did not develop preeclampsia, between patients who did and did not undergo a cesarean delivery, and finally between patients who did and did not deliver a baby with neonatal hypoglycemia.

In addition, each of the five glucose measurements (GCT, fasting OGTT, 1-hour OGTT, 2-hour OGTT, and 3-hour OGTT) was divided into quartiles. For each glucose measurement, outcomes were compared across quartile categories to assess for a step-wise trend between increasing glucose values and adverse outcomes.

Statistical tests used were Pearson's correlation, Student's $t$-test, Chi-square test for trend, and Mann-Whitney U test, as appropriate (IBM SPSS for Windows 22.0, IBM Corp, Armonk, NY). 


\section{Results}

Over the course of the study period, there were 1,042 women with twin pregnancies $>24$ weeks. Of these women, 111 were excluded (14 monoamniotic twins, 17 twin-twin transfusion, 31 pregestational diabetes or gestational diabetes diagnosed prior to 24 weeks, and 49 late transfer or failure to complete GCT). Of the remaining 931 patients, $67(7.2 \%)$ women were diagnosed with GDM based on screening and thus excluded from the study. The remaining 864 women without GDM comprise the study group (-Fig. $\mathbf{1}$ ).

Of these 864 women, 847 women underwent the GCT at 24 to 28 weeks, 229 (27\%) of whom failed the GCT, and underwent the OGTT. A total of 17 women only underwent the OGTT (due to an abnormal GCT prior to 24 weeks). Therefore, we had a total of 847 GCT results and 246 GTT results.

The characteristics of the population and their GCT and OGTT results are shown in - Table 1. Pearson's correlations between each of the five glucose measures (GCT, fasting
OGTT, 1-hour OGTT, 2-hour OGTT, and 3-hour OGTT) and gestational age and birthweights are shown in - Table $\mathbf{2}$. We found significant negative associations between the 2-hour and 3-hour OGTT values and gestational age at delivery and birthweight.

We used Student's $t$-tests to compare mean glucose values between women with and without each of the primary outcomes, and the results are shown in - Table 3 . We did not find any significant differences in mean glucose values between women with and without adverse outcomes, aside from a lower mean fasting OGTT value in women who had a twin with neonatal hypoglycemia ( $72 \pm 6$ vs. $78 \pm 7 \mathrm{mg} / \mathrm{dL}$, $p=0.034$ ). However, on nonparametric testing (MannWhitney U test), this difference was no longer significant: (median value: $25-75$ th percentile) $69 \mathrm{mg} / \mathrm{dL}$ (66-77) versus $77 \mathrm{mg} / \mathrm{dL}$ (73-81), $p=0.194$.

The frequency of outcomes across glucose quartiles for each of the five glucose measures is shown in - Table 4 and depicted in - Fig. 2. For each glucose measurement, increasing quartiles were not associated with an increase in adverse

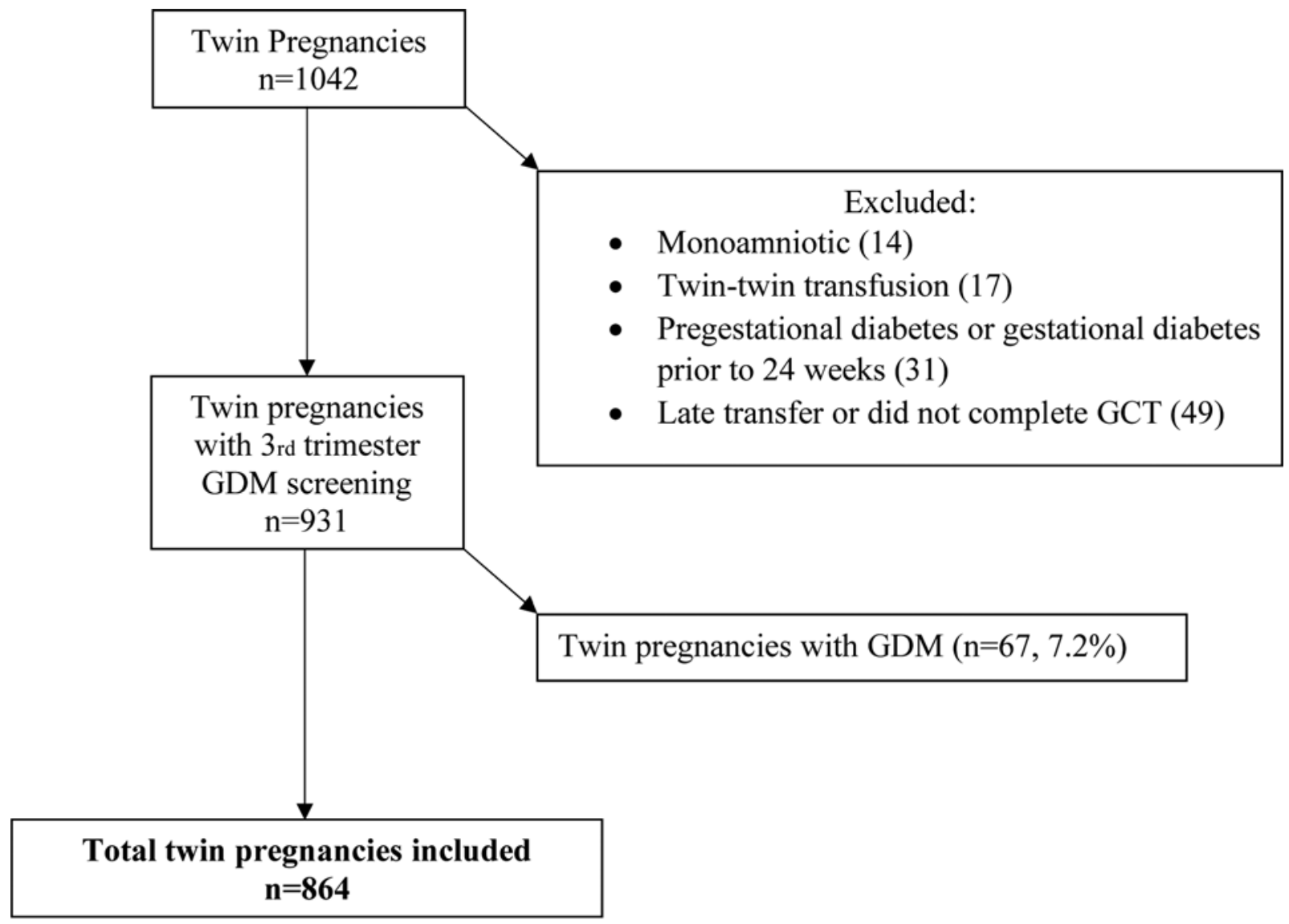

Third trimester GCT, no GDM: $\mathrm{n}=847$

Third trimester OGTT, no GDM: $\mathrm{n}=246$

GDM, Gestational diabetes

GCT, Glucose challenge test (50g)

OGTT, Glucose tolerance test (100g)

Fig. 1 Patient selection. Flow diagram indicating eligibility assessment and inclusion in analyses. 
Table 1 Population characteristics

\begin{tabular}{|c|c|}
\hline Characteristic & Value \\
\hline Number of subjects & 864 \\
\hline Maternal age $(y)$ & $34.0 \pm 6.3$ \\
\hline $\begin{array}{l}\text { Advanced maternal } \\
\text { age ( } \geq 35 \text { years) }\end{array}$ & $378(43.8)$ \\
\hline \multicolumn{2}{|l|}{ Chorionicity } \\
\hline Dichorionic-diamniotic & $727(84.1)$ \\
\hline Monochorionic-diamniotic & 137 (15.9) \\
\hline In vitro fertilization & $478(55.3)$ \\
\hline White race & $752(87.0)$ \\
\hline \multicolumn{2}{|l|}{ Parity } \\
\hline Nulliparous & $514(59.5)$ \\
\hline Multiparous & $350(40.5)$ \\
\hline $\begin{array}{l}\text { Pre-pregnancy body } \\
\text { mass index }\left(\mathrm{kg} / \mathrm{m}^{2}\right)\end{array}$ & $23.2 \pm 4.3$ \\
\hline $\begin{array}{l}\text { Pre-pregnancy obesity } \\
\text { (body mass index } \geq 30 \mathrm{~kg} / \mathrm{m}^{2} \text { ) }\end{array}$ & $67(7.8)$ \\
\hline Gestational age at delivery (wk) & $36.0 \pm 2.3$ \\
\hline Cesarean delivery (all) & 535 (61.9) \\
\hline Cesarean delivery (labored) & $82 / 409(20.0)$ \\
\hline Preeclampsia & $132 / 847^{a}(15.6)$ \\
\hline Birthweight, larger twin (g) & $2,543 \pm 488$ \\
\hline Birthweight, smaller twin (g) & $2,251 \pm 488$ \\
\hline $\begin{array}{l}\text { Neonatal hypoglycemia } \\
\text { of either twin }\end{array}$ & $32(3.7)$ \\
\hline \multicolumn{2}{|l|}{ Diabetes screen results } \\
\hline GCT gestational age (wk) & $26.2 \pm 1.4$ \\
\hline GCT result $(\mathrm{mg} / \mathrm{dL})$ & $118 \pm 24$ \\
\hline OGTT gestational age (wk) & $27.6 \pm 1.8$ \\
\hline Fasting OGTT $(\mathrm{mg} / \mathrm{dL})$ & $77 \pm 7$ \\
\hline 1-hour OGTT (mg/dL) & $151 \pm 23$ \\
\hline 2-hour OGTT (mg/dL) & $128 \pm 23$ \\
\hline 3-hour OGTT (mg/dL) & $102 \pm 26$ \\
\hline
\end{tabular}

Abbreviations: GCT, glucose challenge test $(50 \mathrm{~g})$; OGTT, oral glucose tolerance test $(100 \mathrm{~g})$.

Results listed as $n(\%)$ or mean \pm standard deviation.

${ }^{a}$ Excludes women with chronic hypertension.
Table 3 Comparison of glucose values in women with twin pregnancies with and without adverse outcomes

\begin{tabular}{|c|c|c|c|}
\hline & $\begin{array}{l}\text { Preeclampsia } \\
n=132\end{array}$ & $\begin{array}{l}\text { No preeclampsia } \\
n=715\end{array}$ & $p$-Value \\
\hline $\begin{array}{l}\text { GCT result } \\
(\mathrm{mg} / \mathrm{dL})\end{array}$ & $119 \pm 23$ & $118 \pm 24$ & 0.731 \\
\hline $\begin{array}{l}\text { Fasting OGTT } \\
(\mathrm{mg} / \mathrm{dL})\end{array}$ & $77 \pm 8$ & $78 \pm 7$ & 0.568 \\
\hline $\begin{array}{l}\text { 1-hour OGTT } \\
\text { (mg/dL) }\end{array}$ & $145 \pm 31$ & $152 \pm 21$ & 0.165 \\
\hline $\begin{array}{l}\text { 2-hour OGTT } \\
(\mathrm{mg} / \mathrm{dL})\end{array}$ & $125 \pm 27$ & $128 \pm 22$ & 0.607 \\
\hline \multirow{2}{*}{$\begin{array}{l}\text { 3-hour OGTT } \\
(\mathrm{mg} / \mathrm{dL})\end{array}$} & $96 \pm 29$ & $102 \pm 25$ & 0.206 \\
\hline & $\begin{array}{l}\text { Hypoglycemia } \\
\text { in either twin } \\
n=32\end{array}$ & $\begin{array}{l}\text { No hypoglycemia } \\
\text { in either twin } \\
n=832\end{array}$ & \\
\hline $\begin{array}{l}\text { GCT result } \\
(\mathrm{mg} / \mathrm{dL})\end{array}$ & $112 \pm 25$ & $119 \pm 24$ & 0.167 \\
\hline $\begin{array}{l}\text { Fasting OGTT } \\
(\mathrm{mg} / \mathrm{dL})\end{array}$ & $72 \pm 6$ & $78 \pm 7$ & $0.034^{b}$ \\
\hline $\begin{array}{l}\text { 1-hour OGTT } \\
(\mathrm{mg} / \mathrm{dL})\end{array}$ & $144 \pm 18$ & $152 \pm 23$ & 0.310 \\
\hline $\begin{array}{l}\text { 2-hour OGTT } \\
(\mathrm{mg} / \mathrm{dL})\end{array}$ & $123 \pm 26$ & $128 \pm 23$ & 0.616 \\
\hline \multirow{2}{*}{$\begin{array}{l}\text { 3-hour OGTT } \\
(\mathrm{mg} / \mathrm{dL})\end{array}$} & $94 \pm 22$ & $102 \pm 26$ & 0.357 \\
\hline & $\begin{array}{l}\text { Cesarean } \\
\text { delivery } \\
n=535\end{array}$ & $\begin{array}{l}\text { Vaginal } \\
\text { delivery } \\
n=329\end{array}$ & \\
\hline $\begin{array}{l}\text { GCT result } \\
(\mathrm{mg} / \mathrm{dL})\end{array}$ & $120 \pm 24$ & $117 \pm 24$ & 0.092 \\
\hline $\begin{array}{l}\text { Fasting OGTT } \\
(\mathrm{mg} / \mathrm{dL})\end{array}$ & $78 \pm 7$ & $77 \pm 7$ & 0.423 \\
\hline $\begin{array}{l}\text { 1-hour OGTT } \\
\text { (mg/dL) }\end{array}$ & $152 \pm 23$ & $151 \pm 22$ & 0.675 \\
\hline $\begin{array}{l}\text { 2-hour OGTT } \\
\text { (mg/dL) }\end{array}$ & $129 \pm 23$ & $126 \pm 23$ & 0.443 \\
\hline $\begin{array}{l}\text { 3-hour OGTT } \\
(\mathrm{mg} / \mathrm{dL})\end{array}$ & $103 \pm 26$ & $99 \pm 26$ & 0.189 \\
\hline
\end{tabular}

Abbreviations: GCT, glucose challenge test $(50 \mathrm{~g})$; OGTT, oral glucose tolerance test $(100 \mathrm{~g})$.

a'Student's t-test.

${ }^{\mathrm{b}}$ No longer significant on nonparametric testing (Mann-Whitney $\mathrm{U}$ test).

Table 2 Correlation between glucose measurements and twin pregnancy outcomes

\begin{tabular}{|l|l|l|l|l|l|}
\hline & GCT & Fasting OGTT & 1-hour OGTT & 2-hour OGTT & 3-hour OGTT \\
\hline $\begin{array}{l}\text { Gestational } \\
\text { age at delivery }\end{array}$ & $-0.32(p=0.353)$ & $0.097(p=0.129)$ & $0.020(p=0.755)$ & $-0.169(p=0.008)$ & $-0.177(p=0.006)$ \\
\hline $\begin{array}{l}\text { Birthweight, } \\
\text { larger twin }\end{array}$ & $0.019(p=0.582)$ & $0.123(p=0.055)$ & $0.042(p=0.511)$ & $-0.174(p=0.006)$ & $-0.173(p=0.007)$ \\
\hline $\begin{array}{l}\text { Birthweight, } \\
\text { smaller twin }\end{array}$ & $0.030(p=0.382)$ & $0.124(p=0.053)$ & $0.067(p=0.301)$ & $-0.114(p=0.077)$ & $-0.153(p=0.017)$ \\
\hline
\end{tabular}

Abbreviations: GCT, glucose challenge test $(50 \mathrm{~g})$; OGTT, oral glucose tolerance test $(100 \mathrm{~g})$.

Results listed at Pearson's correlation coefficient ( $p$-value). 
Table 4 Incidence of adverse outcomes, based on glucose value quartiles

\begin{tabular}{|c|c|c|c|c|c|}
\hline GCT & $\begin{array}{l}\text { Quartile } 1 \\
<102 \mathrm{mg} / \mathrm{dL} \\
n=206\end{array}$ & $\begin{array}{l}\text { Quartile } 2 \\
102-115 \mathrm{mg} / \mathrm{dL} \\
n=210\end{array}$ & $\begin{array}{l}\text { Quartile } 3 \\
116-133 \mathrm{mg} / \mathrm{dL} \\
n=207\end{array}$ & $\begin{array}{l}\text { Quartile } 4 \\
\geq 134 \mathrm{mg} / \mathrm{dL} \\
n=224\end{array}$ & $p$-Value ${ }^{a}$ \\
\hline Preeclampsia & 15.2 & 12.4 & 17.2 & 17.7 & 0.275 \\
\hline Cesarean delivery & 54.4 & 65.2 & 62.8 & 64.3 & 0.071 \\
\hline Neonatal hypoglycemia & 5.3 & 2.9 & 4.3 & 2.7 & 0.265 \\
\hline Fasting OGTT & $\begin{array}{l}\text { Quartile } 1 \\
<73 \mathrm{mg} / \mathrm{dL} \\
n=60\end{array}$ & $\begin{array}{l}\text { Quartile } 2 \\
73-76 \mathrm{mg} / \mathrm{dL} \\
n=58\end{array}$ & $\begin{array}{l}\text { Quartile } 3 \\
77-80 \mathrm{mg} / \mathrm{dL} \\
n=56\end{array}$ & $\begin{array}{l}\text { Quartile } 4 \\
\geq 81 \mathrm{mg} / \mathrm{dL} \\
n=72\end{array}$ & \\
\hline Preeclampsia & 18.6 & 17.3 & 18.2 & 15.7 & 0.697 \\
\hline Cesarean delivery & 61.7 & 60.3 & 64.3 & 66.7 & 0.474 \\
\hline Neonatal hypoglycemia & 6.7 & 1.7 & 3.6 & 0 & 0.046 \\
\hline 1-hour OGTT & $\begin{array}{l}\text { Quartile } 1 \\
<139 \mathrm{mg} / \mathrm{dL} \\
n=61\end{array}$ & $\begin{array}{l}\text { Quartile } 2 \\
139-151 \mathrm{mg} / \mathrm{dL} \\
n=60\end{array}$ & $\begin{array}{l}\text { Quartile } 3 \\
152-168 \mathrm{mg} / \mathrm{dL} \\
n=62\end{array}$ & $\begin{array}{l}\text { Quartile } 4 \\
\geq 169 \mathrm{mg} / \mathrm{dL} \\
n=63\end{array}$ & \\
\hline Preeclampsia & 25.4 & 12.3 & 11.5 & 18.6 & 0.326 \\
\hline Cesarean delivery & 62.3 & 58.3 & 62.9 & 69.8 & 0.319 \\
\hline Neonatal hypoglycemia & 4.9 & 3.3 & 1.6 & 1.6 & 0.218 \\
\hline 2-hour OGTT & $\begin{array}{l}\text { Quartile } 1 \\
<113 \mathrm{mg} / \mathrm{dL} \\
n=59\end{array}$ & $\begin{array}{l}\text { Quartile } 2 \\
113-129 \mathrm{mg} / \mathrm{dL} \\
n=64\end{array}$ & $\begin{array}{l}\text { Quartile } 3 \\
130-142 \mathrm{mg} / \mathrm{dL} \\
n=55\end{array}$ & $\begin{array}{l}\text { Quartile } 4 \\
\geq 143 \mathrm{mg} / \mathrm{dL} \\
n=68\end{array}$ & \\
\hline Preeclampsia & 24.1 & 14.5 & 9.6 & 18.8 & 0.386 \\
\hline Cesarean delivery & 59.3 & 60.9 & 70.9 & 63.2 & 0.463 \\
\hline Neonatal hypoglycemia & 5.1 & 3.1 & 1.8 & 1.5 & 0.204 \\
\hline 3-hour OGTT & $\begin{array}{l}\text { Quartile } 1 \\
<82 \mathrm{mg} / \mathrm{dL} \\
n=57\end{array}$ & $\begin{array}{l}\text { Quartile } 2 \\
82-103 \mathrm{mg} / \mathrm{dL} \\
n=64\end{array}$ & $\begin{array}{l}\text { Quartile } 3 \\
104-121 \mathrm{mg} / \mathrm{dL} \\
n=63\end{array}$ & $\begin{array}{l}\text { Quartile } 4 \\
\geq 122 \mathrm{mg} / \mathrm{dL} \\
n=62\end{array}$ & \\
\hline Preeclampsia & 25.0 & 14.8 & 16.7 & 11.9 & 0.095 \\
\hline Cesarean delivery & 63.2 & 54.7 & 68.3 & 67.7 & 0.305 \\
\hline Neonatal hypoglycemia & 3.5 & 4.7 & 1.6 & 1.6 & 0.349 \\
\hline
\end{tabular}

Abbreviations: GCT, glucose challenge test $(50 \mathrm{~g})$; OGTT, oral glucose tolerance test $(100 \mathrm{~g})$.

Results listed as \%.

${ }^{a}$ Chi-square for trend.

outcome frequency for any of the outcomes. However, increasing fasting OGTT quartiles were associated with a lower frequency of neonatal hypoglycemia.

\section{Discussion}

In this study, we found that for women with twin pregnancies without GDM, increasing maternal glucose levels were not associated with measured adverse perinatal outcomes, including preeclampsia, cesarean delivery, and neonatal hypoglycemia.

While existing data indicate that increasing maternal glucose levels in nondiabetic singleton pregnancies are associated with adverse outcomes, our findings suggest that twin pregnancies do not exhibit the same associations. The women in our study with adverse pregnancy outcomes did not have any statistically significant differences in mean glucose values on GCT or OGTT testing compared with women without adverse outcomes. In fact, we initially found that women with the outcome of hypoglycemia of either twin had lower fasting OGTT values than women without this outcome, likely due to the low incidence of neonatal hypoglycemia in our population. This result, however, was no longer significant on nonparametric testing. These findings suggest that while not overtly protective, hyperglycemia in twins may not confer the same risks that it does in singletons.

Our findings call into question the nature of the effect of maternal hyperglycemia on twin pregnancies. Unlike in singletons, where increasing maternal glucose levels are associated with increased risk of adverse perinatal outcomes such as preeclampsia, cesarean delivery, and neonatal hypoglycemia, our data on twin pregnancies suggest a much more equivocal impact. Maternal hyperglycemia may have distinctly different clinical influence on twin gestations due to their altered physiology as compared with singleton gestations. It is even possible that increasing glycemia is somewhat advantageous in twin pregnancies, which is plausible 

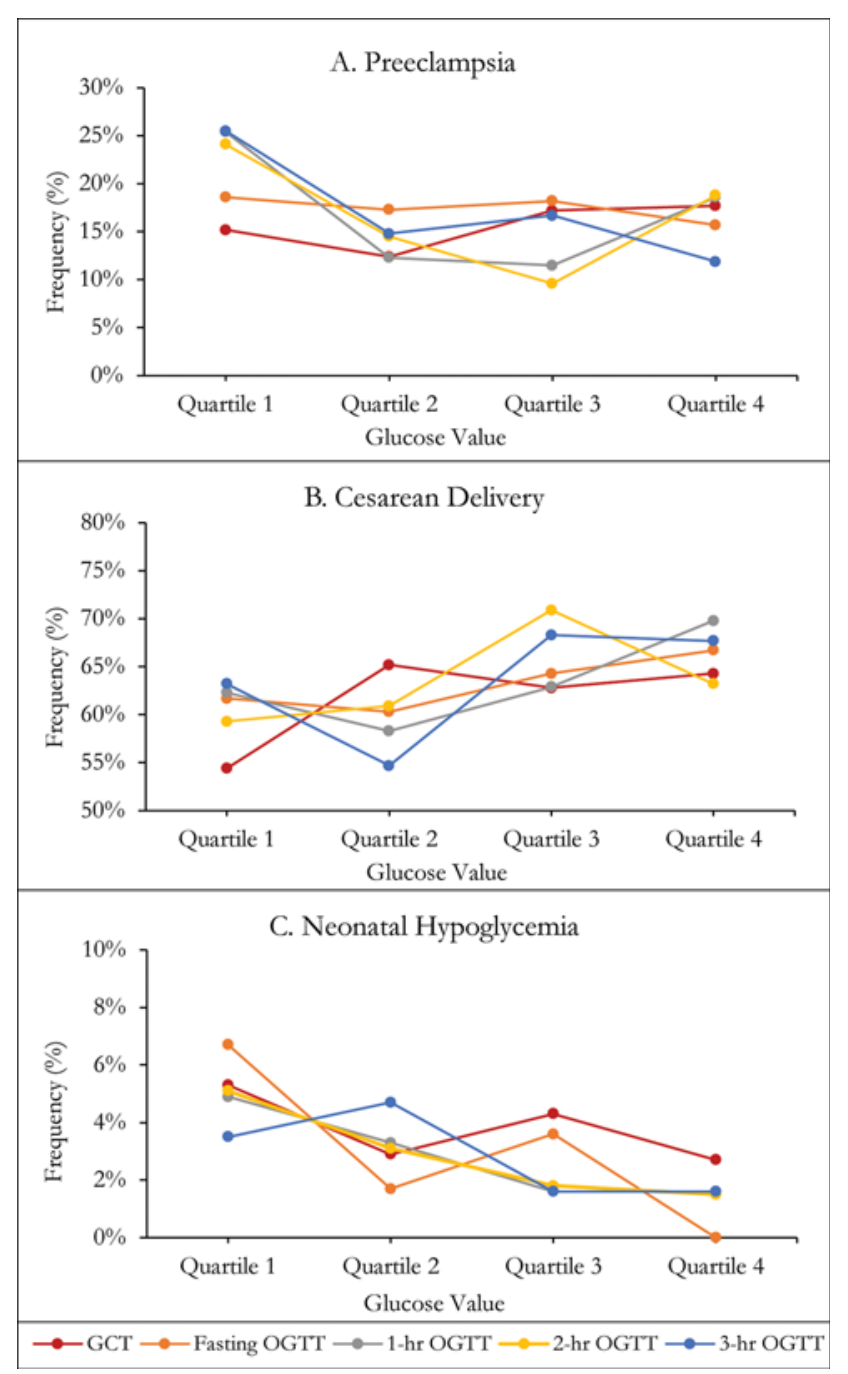

Fig. 2 Frequency of primary outcomes by glucose value quartiles. Glucose quartiles are defined by the following values. GCT: quartile $1,<102 \mathrm{mg} / \mathrm{dL}$; quartile 2, 102 to $115 \mathrm{mg} / \mathrm{dL}$; quartile 3,116 to $133 \mathrm{mg} / \mathrm{dL}$; quartile 4 , $\geq 134 \mathrm{mg} / \mathrm{dL}$. Fasting OGTT: quartile $1,<73 \mathrm{mg} / \mathrm{dL}$; quartile 2,73 to $76 \mathrm{mg} / \mathrm{dL}$; quartile 3,77 to $80 \mathrm{mg} / \mathrm{dL}$; quartile $4, \geq 81 \mathrm{mg} / \mathrm{dL}$. 1-hour OGTT: quartile $1,<139 \mathrm{mg} / \mathrm{dL}$; quartile 2,139 to $151 \mathrm{mg} / \mathrm{dL}$; quartile 3,152 to $168 \mathrm{mg} / \mathrm{dL}$; quartile 4, $\geq 169 \mathrm{mg} / \mathrm{dL}$. 2-hour OGTT: quartile 1, <113 mg/dL; quartile 2, 113 to $129 \mathrm{mg} / \mathrm{dL}$; quartile 3,130 to $142 \mathrm{mg} / \mathrm{dL}$; quartile 4 , $\geq 143 \mathrm{mg} / \mathrm{dL}$. 3-hour OGTT: quartile $1,<82 \mathrm{mg} / \mathrm{dL}$; quartile 2,82 to 103 $\mathrm{mg} / \mathrm{dL}$; quartile 3,104 to $121 \mathrm{mg} / \mathrm{dL}$; quartile $4, \geq 122 \mathrm{mg} / \mathrm{dL}$.

given the increased caloric demand of two fetuses in a twin pregnancy, as compared with a singleton pregnancy. This suggests that the existing data on the positive association between maternal glycemia and adverse perinatal outcomes among singleton pregnancies, as reported by the HAPO study, are not readily applicable to women with twin pregnancies.

Although our study was designed to assess the effects of hyperglycemia below the diagnostic threshold for GDM, our findings are similar to the literature on twin pregnancies with GDM. Several prior studies have reported that when compared with women with non-GDM twin pregnancies, women with GDM twin pregnancies were not at an increased risk of adverse perinatal outcomes. ${ }^{20,21}$ Another study compared outcomes in GDM singleton pregnancies to GDM twin pregnancies and found that GDM was associated with preeclampsia in singletons but not in twins. ${ }^{22} \mathrm{~A}$ recent meta-analysis of 13 observational studies investigated the outcomes of twin pregnancies complicated by GDM and found that with the exception of an increased risk of neonatal intensive care unit admission, GDM in twin pregnancies was not associated with increased risk of respiratory distress, low Apgar's scores, or neonatal hypoglycemia. The results suggested that twin pregnancies with and without GDM were at a similar risk for adverse outcomes. ${ }^{23}$

Optimal glycemic control in twin pregnancies with GDM is also currently unknown. Improved glycemic control through dietary and medication intervention in twin pregnancies with GDM may not improve outcomes such as preeclampsia, early gestational age at delivery, and low birthweight. Instead, strict glycemic control may actually increase the risk of SGA in twin pregnancies with GDM. ${ }^{24}$

Furthermore, the relevance of certain adverse outcomes associated with hyperglycemia and GDM is not as clear in twin pregnancies. While the treatment of GDM in singletons primarily aims to mitigate the risk of macrosomia and associated birth injury, these outcomes are very uncommon in twins. Instead, twin pregnancies are at higher risk for complications such as intrauterine fetal growth restriction. ${ }^{13-15}$ The treatment of GDM in twin pregnancy by restricting caloric intake or using medication to achieve euglycemia may potentially exacerbate such risks.

Our findings suggest that when studying and managing hyperglycemia and GDM during pregnancy, singleton and twin pregnancies should be considered separately as the physiological effects may differ significantly. Future research should attempt to better understand the degree to which hyperglycemia may be beneficial rather than harmful in twin pregnancies and propose new approaches to screening for and treating GDM in twin pregnancies, given that current guidelines are based on data and outcomes in singleton pregnancies.

Limitations of our study include its retrospective and observational design. Our study cohort was from a single obstetric practice, and our population was largely composed of white, nonobese women, and nearly half of whom were advanced maternal age. This might limit the generalizability of our findings to other populations of women with twin pregnancies and different demographics. Nevertheless, the large sample size from a single practice is also a strength of our study, as it increases the reliability of our data due to a single electronic medical record, our confidence in the reliability of our records, and our consistent GDM screening protocol for all women at our practice.

In conclusion, we found that among women with twin pregnancies and no GDM, increasing maternal glycemia was not associated with preeclampsia, cesarean delivery, or neonatal hypoglycemia. This finding differs from what has been demonstrated in singleton pregnancies. The altered physiology of twin gestations may modify the effect of maternal hyperglycemia on perinatal outcomes as compared with singleton pregnancies. Current approaches to screening for and treating GDM during pregnancy might not adequately account for these unique considerations among twins. 


\section{Note}

The findings of this study were presented as a poster presentation at the Society for Maternal-Fetal Medicine's 40th Annual Pregnancy Meeting, February 3 to 8, 2020, in Grapevine, Texas.

\section{Funding}

None.

Conflict of Interest

None declared.

\section{References}

1 Committee on Practice Bulletins-Obstetrics. ACOG practice bulletin no. 190: gestational diabetes mellitus. Obstet Gynecol 2018; 131(02):e49-e64

2 Yogev $\mathrm{Y}$, Xenakis EM, Langer $\mathrm{O}$. The association between preeclampsia and the severity of gestational diabetes: the impact of glycemic control. Am J Obstet Gynecol 2004;191(05):1655-1660

3 Crowther CA, Hiller JE, Moss JR, McPhee AJ, Jeffries WS, Robinson JS; Australian Carbohydrate Intolerance Study in Pregnant Women (ACHOIS) Trial Group. Effect of treatment of gestational diabetes mellitus on pregnancy outcomes. N Engl J Med 2005; 352(24):2477-2486

4 Horvath $\mathrm{K}$, Koch $\mathrm{K}$, Jeitler $\mathrm{K}$, et al. Effects of treatment in women with gestational diabetes mellitus: systematic review and metaanalysis. BMJ 2010;340:c1395

5 Metzger BE, Lowe LP, Dyer AR, et al; HAPO Study Cooperative Research Group. Hyperglycemia and adverse pregnancy outcomes. N Engl J Med 2008;358(19):1991-2002

6 Vahratian A. Prevalence of overweight and obesity among women of childbearing age: results from the 2002 National Survey of Family Growth. Matern Child Health J 2009;13(02):268-273

7 American College of Obstetricians and Gynecologists; Society for Maternal-Fetal Medicine. ACOG practice bulletin no. 144: multifetal gestations: twin, triplet, and higher-order multifetal pregnancies. Obstet Gynecol 2014;123(05):1118-1132

8 Murphy SL, Mathews TJ, Martin JA, Minkovitz CS, Strobino DM. Annual summary of vital statistics: 2013-2014. Pediatrics 2017; 139(06):e20163239

9 Rauh-Hain JA, Rana S, Tamez H, et al. Risk for developing gestational diabetes in women with twin pregnancies. J Matern Fetal Neonatal Med 2009;22(04):293-299

10 Retnakaran R, Shah BR. Impact of twin gestation and fetal sex on maternal risk of diabetes during and after pregnancy. Diabetes Care 2016;39(08):e110-e111
11 Weissman A, Drugan A. Glucose tolerance in singleton, twin and triplet pregnancies. J Perinat Med 2016;44(08):893-897

12 Hiersch L, Berger H, Okby R, et al; for DOH-NET (Diabetes, Obesity and Hypertension in Pregnancy Research Network) and SOON (Southern Ontario Obstetrical Network) Investigators ${ }^{\mathrm{TM}}$. Incidence and risk factors for gestational diabetes mellitus in twin versus singleton pregnancies. Arch Gynecol Obstet 2018;298(03): 579-587

13 Arbuckle TE, Wilkins R, Sherman GJ. Birth weight percentiles by gestational age in Canada. Obstet Gynecol 1993;81(01):39-48

14 Secher NJ, Kaern J, Hansen PK. Intrauterine growth in twin pregnancies: prediction of fetal growth retardation. Obstet Gynecol 1985;66(01):63-68

15 Fox NS, Rebarber A, Klauser CK, Roman AS, Saltzman DH. Intrauterine growth restriction in twin pregnancies: incidence and associated risk factors. Am J Perinatol 2011;28(04):267-272

16 Norwitz ER, Edusa V, Park JS. Maternal physiology and complications of multiple pregnancy. Semin Perinatol 2005;29(05): 338-348

17 Spellacy WN, Buhi WC, Birk SA. Human placental lactogen levels in multiple pregnancies. Obstet Gynecol 1978;52(02):210-212

18 Landon MB, Spong CY, Thom E, et al; Eunice Kennedy Shriver National Institute of Child Health and Human Development Maternal-Fetal Medicine Units Network. A multicenter, randomized trial of treatment for mild gestational diabetes. $\mathrm{N}$ Engl J Med 2009;361(14):1339-1348

19 Carpenter MW, Coustan DR. Criteria for screening tests for gestational diabetes. Am J Obstet Gynecol 1982;144(07): 768-773

20 Okby R, Weintraub AY, Sergienko R, Eyal S. Gestational diabetes mellitus in twin pregnancies is not associated with adverse perinatal outcomes. Arch Gynecol Obstet 2014;290(04):649654

21 Foeller ME, Zhao S, Szabo A, Cruz MO. Neonatal outcomes in twin pregnancies complicated by gestational diabetes compared with non-diabetic twins. J Perinatol 2015;35(12):1043-1047

22 Hiersch L, Berger H, Okby R, et al; DOH-NET (Diabetes, Obesity and Hypertension in Pregnancy Research Network); SOON (Southern Ontario Obstetrical Network) Investigators. Gestational diabetes mellitus is associated with adverse outcomes in twin pregnancies. Am J Obstet Gynecol 2019;220(01):102.e1-102.e8

23 McGrath RT, Hocking SL, Scott ES, Seeho SK, Fulcher GR, Glastras SJ. Outcomes of twin pregnancies complicated by gestational diabetes: a meta-analysis of observational studies. J Perinatol 2017;37(04):360-368

24 Fox NS, Gerber RS, Saltzman DH, et al. Glycemic control in twin pregnancies with gestational diabetes: are we improving or worsening outcomes? J Matern Fetal Neonatal Med 2016;29 (07):1041-1045 